\title{
DA CRÍTICA PLATÔNICA DA ESCRITA À ESCRITA NAS AULAS DE FILOSOFIA
}

\author{
Loan dos Santos Medeiros ${ }^{1}$ \\ Hugo Filgueiras de Araújoº
}

\section{Resumo:}

Esse artigo é uma análise da crítica platônica à escrita com o objetivo de contornar essa crítica em busca de um papel positivo da escrita dentro da experiência filósofica. Em nossa análise trabalhamos com as duas principais obras de Platão no qual o filósofo cita a escrita e sua relação com o pensamento filosófico: Fedro e a Carta Sétima, obras que também são utilizadas pela Escola de Tübingen para defender a existência de um Platão esotérico. Para nossa análise utilizamos autores como Franco Trabattoni, estudioso de Platão, e a pesquisa de Michel Foucault e Pierre Hadot que relacionam a filosofia antiga com o conceito de exercício espiritual no qual a escrita está inserida. Essa concepção de escrita permite a superação da crítica platônica à escrita e assim pensarmos a escrita como um instrumento didático nas aulas de Filosofia. Dessa forma, o uso da escrita em sala aula como um exercício espiritual nos leva a um diálogo com método do Silvio Gallo no qual o ensino de filosofia é apresentado como uma oficina de conceitos.

Palavras-chaves: Filosofia Antiga, Escrita, Ensino de Filosofia.

\section{FROM THE PLATONIC CRITICISM OF WRITING TO THE WRITING IN PHILOSOPHY CLASSES}

\begin{abstract}
:
This article is an analysis of the Platonic critic about writing with the objective of overcome this critic in search of a positive role for writing within the philosophical experience. In our analysis we work with Plato's two main works in which this philosopher quotes writing and its relation to philosophical thought: Phaedrus and the Seventh Letter, works that are also used by the Tübingen School to defend the existence of an esoteric Plato. For our analysis we used authors such as Franco Trabattoni, Plato's scholar, and the research by Michel Foucault and Pierre Hadot who relate ancient philosophy to the concept of spiritual exercise in which writing is inserted. This conception of writing allows the overcoming of Platonic critic to writing and thus we think of writing as a didactic instrument in Philosophy classes. Thus, the use of writing in the classroom as a spiritual exercise leads us to a dialogue with the method of Silvio Gallo in which the teaching of philosophy is presented as a concept workshop.
\end{abstract}

Keywords: Ancient Philosophy, Writing, Philosophy Teaching.

\section{Introdução}

O uso da escrita em sala de aula de Filosofia é um tema presente nos livros didáticos de Filosofia, porém, muitas vezes, colocado como um tema menor, um adendo (suplemento) para a formação filosófica dos jovens. A própria história da filosofia não possui um início

1 Professor da Rede Estadual de Ensino do Ceará. Mestre em Filosofia pelo Programa de Pós-Graduação em Filosofia (Profissional) - UFC. E-mail: medeirosloan1990@ hotmail.com

2 Professor Associado da Universidade Federal do Ceará. Pós-doutorado em Filosofia Antiga e Filologia na Universidade de Atenas - Grécia (2016). Possui Doutorado em Filosofia (Ufpe-Ufpb-Ufrn) pela Universidade Federal da Paraíba (2012). 
positivo da relação entre escrita e filosofia, é o caso do pensamento platônico e sua crítica à escrita, como podemos perceber nas obras Fedro e Carta Sétima. Dessa forma, ao analisarmos a obra de Platão nesse artigo, ao mesmo tempo em que compreendemos as raízes dessa relação complicada entre escrita e filosofia, queremos superá-la em busca de uma fundamentação positiva da escrita nas aulas de Filosofia.

Nossa análise parte do conceito de escrita como exercício espiritual desenvolvida por Foucault, assim como a pesquisa feita pelo estudioso da filosofia antiga, Pierre Hadot, que será de suma importância para nosso trabalho. Não queremos, ao retornar aos clássicos, reproduzi-los em sala de aula, mas encontrar nossos próprios modelos, condizente com a época em que vivemos e com a realidade do ensino em geral e de ensino de filosofia. Em particular, acreditamos poder tomar como exemplo a noção de ensino de filosofia como "oficina de conceitos" desenvolvida por Silvio Gallo, pois apresenta um método de ensino que visa "uma filosofia prática, um conjunto de ferramentas que os jovens percebam como essenciais em sua luta pela sobrevivência cotidiana". (GALLO, 2012, p. 30).

\section{Fedro: Escrita como Phármakon}

No Fedro, Sócrates dialoga com seu discípulo que dá nome ao diálogo acerca do que seria o melhor tipo de relação para um jovem: aceitar um pretendente que o ama ou aquele que não o ama. O diálogo caminha para a compreensão do que seria o verdadeiro amor. $\mathrm{Na}$ parte final do diálogo, Sócrates fala sobre a diferença entre o discurso filosófico e o discurso retórico (esse representado por Lísias, autor do texto que motiva a discussão).

É somente nas partes finais do diálogo [274b - 278b] que Sócrates se debruça sobre a escrita, através do mito de Theuth e o rei Tamos [274c - 275b]. O filósofo descreve a origem da escrita, nela o deus egípcio Theuth (conhecido pelos gregos pelo nome de Hermes) apresenta ao rei Tamos sua invenção, cuja finalidade seria um auxílio à memória, porém o rei observa que a escrita, ao invés de auxiliar a memória, prejudicaria-a, pois aquele que se entregasse à escrita perderia totalmente o desejo de exercitar a memória. O mito de Theuth e as críticas que Sócrates faz à escrita, quando lidas como um recorte do diálogo, são colocados como um "autotestemunho" de Platão da existência de uma doutrina não-escrita.

Dentro dessa multiplicidade de temas abordados dentro de um único diálogo, Trabattoni (2003, p. 106) acentua que a diferença entre o filósofo e o retor é a motivação principal do texto platônico, defendendo que o filósofo dispõe de determinados conhecimentos que a retórica não possui. A relação entre o Eros e a retórica já é conhecida, pois esta busca

\begin{tabular}{|c|c|c|c|c|}
\hline Rovista Dialectus & Ano 9 & n. 20 & Outubro - Novembro 2020 & p. $71-83$ \\
\hline
\end{tabular}


persuadir o seu ouvinte a uma determinada forma de pensar ou agir, ou seja, pela força dessa persuasão “os homens são arrastados para determinadas coisas, ou a cumprir determinadas ações, graças a um impulso que não se baseia nas argumentações, mas tem a natureza do impulso afetivo e emocional" (ibidem, p. 111). Platão irá aproximar, no Fedro, a filosofia a essa força irracional que é a loucura [manía], tal força irracional nem sempre é negativa, mas possui qualidades positivas, pois "os maiores bens, quando dados por graça divina, nos vêm mediante a loucura" [244a]; e Sócrates apresenta quatro tipos de loucuras boas: a profética, a expiatória, a poética e a que nos importa aqui, a paixão erótica, "aquela que, quando alguém ao ver o belo daqui, do verdadeiro tendo uma reminiscência, torna-se alado e uma vez provido de novas asas deseja ardentemente voar" [249d]. Desta forma, podemos compreender que a beleza seria "o único resquício de ideia conservado na realidade sensível” (TRABATTONI, 2010, p. 59). Porém, o que caracteriza o discurso belo? Essa investigação se inicia na passagem 259e: "qual é a maneira bela de proferir e escrever discursos e qual a não bela".

Segundo Trabattoni, Platão estaria tentando conciliar a fragilidade do lógos com a necessidade de um discurso racional que tenta se opor ao relativismo de Protágoras. Assim sua intenção "era salvaguardar uma verdade útil para a vida prática, tendo em conta todos os obstáculos que se interpõem à sua obtenção" (TRABATTONI, 2003, p. 101). Dessa forma, enquanto os deuses podem alcançar à sophía, aos mortais está destinada a prática da filosofia, e devem conviver com essa limitação. A crítica à escrita aparece nesse contexto de análise do discurso e daquilo que o tornaria belo, ou seja, instrumento para o filosofar.

Platão desconfia da escrita, não por ela se opor a um saber oral difundido entre iniciados, mas porque ela fixa a doutrina, dando assim a impressão de que o essencial é a própria doutrina (cf. ibidem, p.100). Na passagem 275a, Tamos responde ao Theuth, mostrando o equívoco que ela pode gerar:

aos que receberem essa instrução [escrita] concedes uma aparente e não verdadeira sabedoria. Pois, graças a ti, vão ouvir falar de muita coisa que não aprenderam e serão aparentemente sabidos em tudo, quando ignoram a maior parte - e ainda de convívio difícil -, feitos sábios em aparências e não em saberes [275b].

Esta ilusão de conhecimento que a doutrina escrita oferece engana um leitor desatento que orgulhosamente acredita possuir um saber que na verdade é aparente, pois o verdadeiro conhecimento não estaria no texto escrito. A escrita só tem um valor para aquele que já sabe, que possui um conhecimento adquirido de outra forma. Theuth havia descoberto um medicamento para as recordações e não para a memória.

\begin{tabular}{|l|l|l|l|l|}
\hline Q & Anoista 9 & n. 20 & Outubro - Novembro 2020 & p. 71 - 83 \\
\hline
\end{tabular}




\title{
DA CRÍTICA PLATÔNICA DA ESCRITA À ESCRITA NAS AULAS DE FILOSOFIA
}

Loan dos Santos Medeiros / Hugo Filgueiras de Araújo

A escrita, que inicialmente é apresentada como um pharmakón, que não possui um valor intrínseco, mas decorrente da avaliação do deus-rei (e depois da análise de Sócrates), como observa Derrida (2005, p. 22), é rejeitada como algo exterior ao verdadeiro conhecimento, por não só confundir a memória viva e conhecedora (mnémé) que estaria presente na forma de conhecimento como anamnese com a recordação (hupómnésis). Dessa forma, a escrita não seria neutra, mas "é essencialmente nociva, exterior à memória, produtora não de ciência, mas de opinião, não de verdade, mas de aparência” (ibidem, p. 50). A hupómnésis seria uma imitação, simulacro, da memória viva, sobre a qual se funda o verdadeiro conhecimento. Essa valorização da hupómnésis pelo phármakon afetaria a própria mnémé, colocando uma aparente (dóxan) sabedoria no lugar da verdadeira (alétheian) sabedoria. Podemos reconhecer nessa passagem uma reversão feita pelo deus Tamos: “A escritura anunciada por Theuth como um remédio, como uma droga benéfica, é em seguida devolvida e denunciado pelo rei, depois, no lugar do rei, por Sócrates, como substância maléfica e filtro do esquecimento.” (DERRIDA, 2005, p. 74)

Além de ser danosa à memória, a escrita introduziria no pensamento filosófico uma rigidez falsa que enganaria o leitor. Essa noção de saber rígido se opõe ao projeto platônico, uma continuação do fazer filosófico de Sócrates, como assinala Trabattoni (2003, p. 29)

\begin{abstract}
Decidido a fazer filosofia continuando o trabalho de Sócrates e com os olhos concentrados sobre os negativos resultados da prática ética e política vigente da sua cidade, Platão inaugura então uma ideia de filosofia na qual o saber que se procura não é um saber que se encerra em si mesmo, voltado para o puro conhecer, mas é um saber que pretende identificar aqueles princípios gerais fundamentais, os únicos que podem promover o bem-estar do homem (ou seja, sua felicidade), tanto na vida privada como na vida pública.
\end{abstract}

A periculosidade dessa droga estaria em que sua exterioridade ao pensamento afetaria o lógos verdadeiro, destituindo de sua natureza e lhe dando uma característica que não é mais a sua, conforme aponta Derrida (2005, P. 57): "Platão mantém tanto a exterioridade da escritura como seu poder de penetração maléfico, capaz de afetar ou infectar o mais profundo". Desta forma, se a escrita possui esse caráter que levaria o seu leitor ao equívoco, ela deveria ser substituída por um recurso mais eficaz, o discurso oral. Daí Platão afirmar a superioridade do discurso oral em relação ao escrito,

uma comunicação oral é mais verdadeira, em geral, do que uma escrita não porque possa dizer coisas mais verdadeira, mas porque pode mostrar, promover e reproduzir

\begin{tabular}{|l|l|l|l|l|}
\hline Q Rovita Qialectus & Ano 9 & n. 20 & Outubro - Novembro 2020 & p.71-83
\end{tabular}




\section{DA CRÍTICA PLATÔNICA DA ESCRITA À ESCRITA NAS AULAS DE FILOSOFIA}

Loan dos Santos Medeiros / Hugo Filgueiras de Araújo

a verdade das almas (isto é, no único lugar onde a verdade se encontra) muito melhor do que tudo o que possa fazer o escrito. (TRABATTONI, 2003, p. 145. Grifo do autor)

A força persuasiva da fala diante da escrita leva Platão a preferir a primeira em detrimento da segunda, uma vez que ao escrever, escrevemos para todos, não podendo ser adaptada às necessidades e aos questionamentos dos possíveis interlocutores. É o que também reconhece Derrida (2005, p. 60) “o escrito enquanto se repete e permanece idêntico a si no tipo, não se curva em todos os sentidos, não se dobra às diferenças entre os presentes, às necessidades variáveis, fluidas, furtivas da psicagogia”. E essa imagem do lógos não é nova para a filosofia, os sofistas, tal como Górgias, já apresentavam um lógos com tal função e acreditavam que o "o phármakon está compreendido na estrutura do lógos" (ibidem, p. 62).

A escrita é ainda retratada para Platão como um jogo quando compara o uso da escrita pelo filósofo com o jardim de Adônis, aferindo-o à imagem de um agricultor sensato utilizando da metáfora do Jardim de Adônis:

O lavrador inteligente, que cuida das sementes e quer torná-las fecundas, lavraria a sério e em pleno verão os jardins de Adônis, alegrando-se ao vê-las belas e a germinar em oito dias? Ou executaria essas coisas por ocasião de uma festividade e divertimento, se é que as faz? (276b)

De acordo com esse costume, eram separadas algumas sementes após a colheita de verão. Estas eram plantadas em tigelas e cuidadas para que em pouco tempo brotassem exuberantes, contudo, ao serem expostas rapidamente, murchavam. Os restos eram lançados ao mar ou em fontes pelas mulheres entre lamentos ritualísticos. A noção de jogo (paidiá) é introduzida aqui de uma forma negativa. O jogo é perigoso, como foi o destino da jovem Orítia no mito apresentado; no diálogo, a própria noção de jogo aparece na ambivalência do phármakon que Platão busca orientar.

Assim, a escrita seria sempre de uso dúbio, gerando filhos bastardos, e por mais que Trabattoni (2003, p. 154) reconheça a debilidade do lógos como nos dois tipos de discursos e que até o discurso oral é "dependente de um saber não discursivo que, em última análise, é pai de todas as altas e baixas formas de saber acessíveis ao homem”. Contudo, o ele reconhece que essa debilidade do recurso da escrita é sempre enfraquecido, o que o leva a reconhecer ainda uma primazia da oralidade em relação à escrita pelo "desejo de garantir a adaptabilidade do discurso filosófico aos vários tipos de alma" (TRABATTONI, 2003, p. 149). O filósofo deve possuir algo além das sementes utilizadas no Jardim do Adônis, que servirá de base para construção não só de seus escritos, mas para construir discursos sempre diversos conforme a 
necessidade do seu interlocutor. Dessa forma, o sábio não deve apenas conhecer seu objeto, mas também a alma para quem deve divulgar sua ciência e adequar seu discurso a esse ouvinte:

\footnotetext{
Quem é sábio, por isso, considerará o discurso escrito sempre como um jogo, e estará convicto de que nunca tenha sido escrito nem pronunciado nenhum discurso digno de grande consideração, em particular por aqueles que os compõem somente para persuadir (ibidem, p. 149-150)
}

Dessa forma, Trabattoni reafirma a crítica platônica à escrita ao colocá-la como exterior àquilo que realmente caracteriza o conhecimento, seja "a alma como lugar onde ocorre o único verdadeiro aprendizado possível” (TRABATTONI, 2003, p. 141). A exterioridade da escrita em relação ao ser é aquilo que Derrida (1999, p. 42) caracteriza como a tradição platônica/ocidental da escrita: "o Fedro denunciava a escritura como intrusão da técnica artificiosa, efratura de uma espécie totalmente original, violência arquetípica: erupção do fora no dentro". Por mais que compreendamos, através de Trabatonni, a relação entre oralidade e escrita na obra de Platão, há ainda nela a construção de uma hierarquia entre esses dois elementos. Ao meu ver, a Carta Sétima lança luz sobre a motivação dessa decisão, que possui raízes éticas.

\section{Carta Sétima: "Não há obra minha escrita"}

Diferente do Fedro, a Carta Sétima tem sido motivo de debate quanto à sua autenticidade. Não são poucos os debates acerca da autoria não só desta carta como de todas aquelas que compõem a coletânea de epístolas supostamente escritas por Platão. Claro, algumas são definitivamente reconhecidas como falsas, porém a autenticidade da Carta Sétima ainda é, por si só, um tema para pesquisa.

Todavia, como reconhece Irwin na introdução à Carta VII (in: PLATÃO, 2008, p. 40), por mais que se duvide acerca da autenticidade da carta, devemos aceitar que o seu autor não é um simples leigo, mas um conhecedor do estilo platônico e era íntimo do ambiente platônico, ou seja, mesmo que não estejamos diante de uma obra escrita por um Platão já maduro, ela seria escrita por alguém que estaria na esteira da recepção do pensamento platônico, e nossa preocupação está não em seu autor, mas em como sua obra tornou-se importante para a percepção da relação entre escrita e filosofia.

É o caso da interpretação da Escola de Tübingen e Milão, ao tomarem a autenticidade da Carta Sétima, um dos elementos que argumentam a favor da existência de uma tradição oral em Platão que não estaria presente em seus escritos. Por sua vez, Trabattoni se

\begin{tabular}{|l|l|l|l|l|}
\hline Gevista Oialectus & Ano 9 & n. 20 & Outubro - Novembro 2020 & p. 71-83 \\
\hline
\end{tabular}


debruça sobre essa carta, não discordando da sua autenticidade, como fazem alguns críticos da existência da tradição oral platônica, mas para mostrar que a carta aponta para resultados opostos àqueles esperados por estudiosos como Giovanni Reale.

$\mathrm{O}$ tema da crítica à escrita se torna ainda mais forte quando nos aproximamos da citação platônica da Carta Sétima: "Não há obra minha escrita" [341c], que é utilizada como uma das provas que Platão não escreveu seu pensamento, sua filosofia, mas que os diálogos platônicos funcionam como uma 'propedêutica' para a doutrina que seria ensinada oralmente, trazemos então a citação completa para vermos o seu contexto:

Sei que alguns outros escreveram sobre essas mesmas coisas, mas esses não sabem
nem de si mesmos. Eis o que tenho a explicar acerca de todos que escreveram e hão
de escrever, quanto dizem saber acerca daquilo que me ocupo, tanto os que me
ouviram a mim, como a outro, como ainda os que encontraram por si. Não é possível,
na minha opinião, que tenham compreendido nada do assunto [prágmatos]. Não há
obra minha escrita sobre ele, nem jamais poderá haver. Pois, de modo algum se pode
falar disso, como de outras disciplinas [mathémata], mas depois de muitas tentativas,
com a convivência gerada pela intimidade, como um relâmpago brota uma luz nasce
na alma e se alimenta a si própria. [341b-c]

Trabatoni nos sugere que pode também significar "aquilo que muito me interessa" (ibidem, p. 173), mostrando que Platão possuía uma dedicação especial a um assunto, um pragmatos, que pode ser interpretada como uma alusão às doutrinas orais, porém, aqui, aqueles que afirmam escrever essa doutrina caem em contradição, pois Platão interdita a escrita dessa doutrina esotérica não como um problema contextual de sua época, como pensam os tubinguenses, que julgam poder escrever atualmente aquilo que Platão ensinava apenas oralmente, mas o autor da Carta Sétima afirma a impossibilidade de escrever sobre esse tema $a$ qualquer época e aquele que o faz demonstra não conhecer a sua filosofia.

Desta forma, Trabattoni está afirmando que não apenas não existe uma doutrina oral em Platão ensinada de forma esotérica, mas que o que este está se referindo ao 'o que muito me interessa' não é uma doutrina ensinável como ocorre com as demais ciências que o autor da Carta Sétima se refere como mathémata, mas um saber específico que o saber filosófico cuja passagem se dá de forma imediata, tal como um relâmpago. Se existisse um sistema a ser conhecido, a imagem do relâmpago não caberia aqui, mas seria ideal uma metáfora de algo que construído lentamente tal como uma casa e esse sistema poderia ser ensinado seja pela escrita seja pela fala (cf. ibidem, p. 179).

Ora, o que está em jogo aqui é um saber que é diferente das outras disciplinas [mathémata], não se pode adequá-lo a esse tipo de discurso. Sobre esse tema, Foucault (2010a,

\begin{tabular}{|l|l|l|l|l|}
\hline Gevista Oialectus & Ano 9 & n. 20 & Outubro - Novembro 2020 & p. 71 - 83 \\
\hline
\end{tabular}


p. 225) acrescenta que para o autor da Carta Sétima: “As coisas não acontecem assim, não é o fio das mathémata que a filosofia se transmite"; contudo qual será a forma se alcançar o saber filosófico? Platão afirma em seguida que é pela "convivência gerada pela intimidade”, ou seja, não há conhecimento filosófico quando não há um envolvimento, uma intimidade, uma convivência daquele que quer conhecer com o conhecido. Dessa forma, o conhecimento filosófico não é só diferente das demais disciplinas [mathémata], mas segue um caminho oposto,

\begin{abstract}
Nas mathémata não há synousía, não é preciso syzên. (...) Esses matemas têm de ser transmitidos e têm de ser guardados no espírito até que, eventualmente, o esquecimento os apague. Aqui, ao contrário, não há fórmula, mas uma coexistência. Não há aprendizado de fórmula por alguém, mas acendimento brusco e súbito da luz no interior da alma. E não [há] tampouco inscrição e depósito na alma de uma fórmula feita, mas alimentação perpétua da filosofia pelo óleo secreto da alma. (ibidem, p. 226)
\end{abstract}

Logo, não haverá obras escritas sobre esse conhecimento, pois isso daria, tal como Sócrates afirma no Fedro, uma falsa ilusão de um saber que seria transmitido pela escrita às massas e estagnariam nessa forma de saber, acreditando serem "doutos em coisas venerandas" [341e] e a escrita não seria capaz de persuadi-las, de continuar em frente, e mesmo a presença do mestre é reduzida, pois Platão reconhece que aqueles que irão buscar o conhecimento filosófico o fazem "com pequenas indicações" [341d];

E qual seria o assunto da filosofia? É o que Platão indica a Dionísio quando o experimenta. Ele afirma que "é preciso indicar a essa gente que todo o assunto [prâgma] exige trabalho, e que do trabalho vem a fadiga", aqui o termo possui duas conotações tanto o referente de um termo, no caso aquilo que a filosofia se refere, "seu assunto", e o outro é aquilo que nos ocupa em oposição ao ócio. Conforme Foucault,

\footnotetext{
os prágmata são as atividades, tudo aquilo que nos ocupamos, tudo aquilo a que podemos nos dedicar. E prágmata, como vocês sabem, se opõe nesse sentido a skholé, que é o lazer. Para dizer a verdade, a skolé filosófica, esse lazer filosófico consiste precisamente em se ocupar de um certo número de coisas que são os prágmata da filosofia" (FOUCAULT, 2010a, p. 218)
}

Platão destaca assim a diferença do conhecimento filosófico das demais disciplinas, essas chamadas de mathématas, pois a filosofia seria um determinado modo de vida que se alcança com bastante esforço. O filosofar é, portanto, "toda uma série de atividades e de prágmata que constituem as práticas filosóficas. [...] o real da filosofia, aquilo a que se refere a

\begin{tabular}{|c|c|c|c|c|}
\hline Rovista Oialectus & Ano 9 & n. 20 & Outubro - Novembro 2020 & p. $71-83$ \\
\hline
\end{tabular}


palavra filosofia é um conjunto de prágmata (de práticas)”. (FOUCAULT, 2010a, p. 218). E em seguida Platão cita um conjunto de atividades que podemos chamar de um modo platônico de vida: ser bom aluno (eumathés), ter boa memória (mnémona), ser apto nos cálculos (logízesthai dunatòs) e sóbrio, em si mesmo. [cf. 340d] E que o indivíduo que queira realmente fazer filosofia deve buscar exercitar essas qualidades e deve odiar qualquer modo de vida contrário a este. Vemos então que Platão nos apresenta um determinado modo de vida entendido como o seu 'alimento de cada dia', um exercício diário. Desta forma, acreditamos encontrar através dessa relação entre modo de vida e filosofar, o caminho que Platão abre para repensar uma possível relação entre escrita e filosofia, ao pensar a escrita não como um instrumento do mathémata, como apontou, mas como um exercício espiritual.

Ao falarmos da prática filosófica como modo de vida estamos nos referindo a um conjunto de práticas que foram utilizadas durante a história da filosofia como "práticas espirituais" (áskesis). Dentre elas, podemos citar a prática da escrita que foi vista por alguns filósofos helenistas como um método valioso de cuidado de si, é o que relata Foucault ao analisar as chamadas Escritas de Si. Nesse estudo sobre o uso da escrita pelos filósofos helenistas, Foucault (2014, p. 143) afirma: "Nenhuma técnica, nenhuma habilidade profissional pode ser adquirida sem exercício; não se pode mais aprender a arte de viver, a technê tou biou, sem uma áskesis que deve ser compreendida como um treino de si por si mesmo", a escrita, portanto é, enquanto prática ascética, uma ação do indivíduo sobre si mesmo e, então, uma "prática de autoformação do sujeito" (ibidem, p. 259).

A escrita não pode ser resumida a uma reprodução, seja dos sons, seja do pensamento, mas deve ser considerada como uma "tecnologia de si" participando ativamente da experiência filosófica como experiência de autotransformação. Tais práticas podem ser compreendidas tanto por Hadot como por Foucault como práticas espirituais, entendendo espiritualidade como aquela que "postula a necessidade de que o sujeito modifique-se, transforme-se, desloque-se, torne-se, em certa medida e até certo ponto, outro que não ele mesmo" (FOUCAULT, 2010a, p. 16), não havendo atrito aqui entre o que se compreende por filosofia e espiritualidade, pois como afirma Ortega:

a filosofia é atividade de autotransformação, atividade correspondente na Antiguidade à espiritualidade, filosofia como experiência da espiritualidade, ou seja, as transformações que o sujeito deve desenvolver para alcançar uma determinada forma de existência. (ORTEGA, 1999, p. 57)

\begin{tabular}{|l|l|l|l|l|}
\hline Qevista Qialectus & Ano 9 & n. 20 & Outubro - Novembro 2020 & p. 71 - 83 \\
\hline
\end{tabular}


É aqui que inserimos o papel da escrita, não como cópia do discurso oral, como afirmava Platão no Fedro, mas como espaço de exercício filosófico na qual o aluno poderá ter a experiência filosófica.

\section{Escrita como Exercício Espiritual}

Contudo, de que forma podemos pensar a escrita como exercício espiritual para além das escolas filosóficas da Grécia Antiga e no contexto atual do ensino de filosofia no Brasil? Uma grande ferramenta que o professor pode se utilizar é da "dissertação filosófica" que já aparece na literatura sobre ensino de filosofia.

A oficina de conceitos, apresentada por Silvio Gallo, é um método que orienta a prática de ensino de filosofia, composto de quatros momentos: sensibilização, problematização, investigação e conceituação. Nos dois últimos momentos a escrita aparece como importante ferramenta, uma vez que a investigação se utiliza do texto escrito enquanto fonte de informação acerca do problema filosófico a ser investigado e tem no uso da escrita sua efetivação. Conforme Dominique Folscheid, a escrita pode ser entendida como "o exercício filosófico por excelência" e ele ainda acrescenta:

Não há melhor lugar para exercitar nosso pensamento sobre um tema preciso, para analisar e produzir conceitos articulando-os dentro e através de um discurso, não há outro meio de colocar-nos na necessidade de ter de construir uma problemática, Em suma, a dissertação, em filosofia, é insubstituível, essencial: tem a ver com a essência do ato de filosofar. (FOLSCHEID; WUNENBURGER, 1997, p. 158 e 159)

Leitura e escrita portanto permitem ao aluno exercitar o filosofar e estão intrinsecamente relacionados, porém alguns problemas se levantam acerca do uso do texto escrito e da sua interpretação, é um dos problemas do Fedro de Platão que não analisamos na parte anterior, mas ao qual nos remetemos agora: a crítica feita por Sócrates a orfandade do texto filosófico.

Pois há algo de terrível na escrita, Fedro, e que se assemelha realmente à pintura. Pois os produtos desta estão postos como serres vivos, mas, ao interrogá-los sobre algo se mantêm em silêncio solene. E o mesmo se dá com os discursos: parecerá a ti que falam pensando por si mesmo, mas, ao interrogá-los querendo aprender sobre o que quer que tenham dito, indicam sempre uma única e mesma coisa. E uma vez escrito, todo discurso roda por toda parte, do mesmo modo - entre os que o compreendem bem como entre aqueles aos quais não convém -, e não sabem com que devem ou não falar. E quando sofre ofensas e insultos injustamente sempre precisa da ajuda de seu pai: pois ele próprio não é capaz de defender e nem de ajudar a si mesmo. [275d]

\begin{tabular}{|c|c|c|c|c|}
\hline Rovista Oialectus & Ano 9 & n. 20 & Outubro - Novembro 2020 & p. $71-83$ \\
\hline
\end{tabular}




\section{DA CRÍTICA PLATÔNICA DA ESCRITA À ESCRITA NAS AULAS DE FILOSOFIA}

Loan dos Santos Medeiros / Hugo Filgueiras de Araújo

Para Sócrates, o discurso escrito sempre necessita do discurso oral como modelo e como forma de ajuda ao texto escrito. O texto escrito seria uma reprodução do texto oral, como a pintura dos seres vivos, e o leitor deve acessar esse sentido oculto. Porém, a leitura não é um processo passivo de absorção de conhecimento, mas é uma construção de sentido, conforme Bajard (2014, p. 41): "Ler é saber construir sentido a partir de um significante escrito cuja coerência se encontra ao nível do texto inteiro". O processo de leitura é, portanto, um processo ativo, em que o leitor entra em interação com o texto, não captando um sentido puro, mas sendo partícipe de um processo de produção de sentido atual:

O sentido é reconhecido como o produto da interação entre um sujeito e um texto. Este último não pode ser considerado como um tesouro a ser desenterrado. Não se trata somente de ativar um sentido presente no texto, mas também de produzir esse sentido a partir das interações entre as experiências do sujeito e o material gráfico. (ibidem p. 42)

Claro que Bajard se refere à leitura de textos em geral, e não em termos específicos do texto filosófico; outro autor que se dedica à leitura específica do texto filosófico, Frederic Cossutta, reafirma o ato de leitura como um processo ativo, em que o leitor deve fazer operações para alcançar uma leitura verdadeiramente filosófica:

Não se pode considerar um texto filosófico como se formado unicamente por sequências lineares sucessivas. A leitura torna a se desdobrar, num espaço de múltiplas dimensões, um processo complexo que hierarquiza, focaliza ou recorta planos; que compõem, liga ou diferencia a operações igualmente complexas (COSSUTA, 1997, p. 211).

O texto filosófico é específico e se expressa por diversos gêneros que o aluno de Filosofia deve conhecer, tais como aforismas, diálogos, cartas, tratados, entre outros. A ausência do autor, o seu apagamento não deve ser visto como um entrave para uma apreensão do significado do texto. A crítica do Fedro não está pautada no silêncio ou no esvaziamento de significado no texto escrito, mas, pelo contrário, na multiplicidade que o texto escrito carrega em si, como aponta Rancière (1995, p. 9):

Nele[Fedro], a escrita sofre a dupla crítica, aparentemente contraditória, de ser ao mesmo tempo muda e falante demais. Ela é muda. Entendamos com isso que não há nenhuma voz presente para dar às palavras que ela arruma o tom da verdade delas, para acompanhá-las de modo a semeá-las no espírito preparado para recebê-las e fazêlas frutificar. A escrita está liberta do ato de palavra que dá a um logos a sua legitimidade, que o inscreve nos modos legítimos de falar e do ouvir, dos enunciadores e dos receptores autorizados. É por isso, também, que ela é falante demais: a letra morta vai rolar de um lado para o outro sem saber a quem se destina, a quem deve, ou

\begin{tabular}{|l|l|l|l|l|}
\hline Govista Qialectus & Ano 9 & n. 20 & Outubro - Novembro 2020 & p. 71 - 83 \\
\hline
\end{tabular}




\section{DA CRÍTICA PLATÔNICA DA ESCRITA À ESCRITA NAS AULAS DE FILOSOFIA}

Loan dos Santos Medeiros / Hugo Filgueiras de Araújo

não, falar. Qualquer um pode então, apoderar-se, dar a ela uma voz que não é mais “a dela", construir com ela uma outra cena de fala, determinando uma outra divisão do sensível

Aquilo que Platão critica no texto escrito, a orfandade do texto filosófico, seria a sua principal potência, que podemos utilizar em sala de aula, pois permite a multiplicidade e o aparecimento das diferenças. O texto escrito seria então a base da experiência do pensamento e a razão do seu uso em sala de aula: um espaço de apropriação que geraria uma outra cena de fala, permitindo uma democracia autêntica, não baseada no consenso. Entendemos como "democracia autêntica" aquilo que escreve Gallo (2012, p. 49) ao afirmar que na democracia do consenso existe "apagamento do diferente, de perpetuação do mesmo; em contrapartida, uma democracia fundada no dissenso é aquela em que a diferença emerge."

O texto escrito, por permitir que o discurso caminhe livremente, órfão, permite então a sua apropriação por um maior número de indivíduos. A escrita, que gera uma livre apropriação de ideias e sua reformulação, perturbava Platão, pois está intimamente ligada àquele regime político que tanto ele criticou: a democracia, como afirma NASCIMENTO (2004, pg.25): "Notamos nas palavras de Sócrates que de algum modo a escrita tem uma função democrática o que atrapalha certamente a soberania do rei Thamuz".

Da mesma forma, a dissertação filosófica faz emergir diferença no processo de aprendizagem, aquilo que o aluno produz não pode ser corrigido de forma padrão, mas deve ser lido em sua singularidade, conforme afirmam Folscheid e Wunenvurger (1997, p. 159): "Em dissertação [filosófica] não há resposta única, mas respostas, uma multiplicidade de respostas possíveis, uma 'democracia' de respostas filosóficas.”

Assim, não podemos falar em um exercício da escrita em sala de aula excluído da leitura do texto de filósofos, que servirão de base para uma apropriação dos conceitos e parâmetros para uma escrita filosófica. Acreditamos que esse processo está em sintonia com a noção de ensino de filosofia como criação de conceitos, que desenvolvemos acima, em que a investigação pressupõe a leitura e a conceituação encontra na escrita uma forma de manifestação. Não queremos com isso afirmar que as aulas de filosofia sejam resumidas em leitura e produção de textos filosóficos, isso seria negar a realidade atual da educação básica brasileira. Há diversas dificuldades com a leitura do texto filosófico e o exercício da escrita filosófica é algo que requer um grande esforço, porém necessário para que os alunos da educação básica, principalmente pública, possam ter acesso à experiência filosófica que o texto escrito propicia.

\begin{tabular}{|c|c|c|c|c|}
\hline Rovista Qialectus & Ano 9 & n. 20 & Outubro - Novembro 2020 & p. $71-83$ \\
\hline
\end{tabular}




\section{Referências}

BAJARD, Élie. Caminhos da escrita: espaço de aprendizagem. São Paulo: Cortez, 2014.

DERRIDA, Jacques. Gramatologia. São Paulo: Editora Perspectiva, 1999.

DERRIDA, Jacques. Farmácia de Platão. São Paulo: Iluminuras, 2005.

FOUCAULT, Michel. O Governo de SI e dos outros: cursos no Collèhe de France. São Paulo: Editora WMF Martins Fontes, 2010a.

FOLSCHEID, Dominique, WUNENBURGER, Jean-Jacques. Metodologia Filosófica. São Paulo: Martins Fontes, 1997.

GALLO, Silvio. Metodologia do ensino de filosofia: Uma didática para o ensino médio. Campinas, SP: Papirus, 2012.

GALLO, Silvio. Filosofia: Experiência do Pensamento. 2a Ed. São Paulo: Scipione, 2016.

HADOT, Pierre. O que é Filosofia Antiga? São Paulo: Edições Loyola, 5a ed., 2011

NASCIMENTO, Evandro. Derrida. Rio de Janeiro: Jorge Zahar, 2004.

ORTEGA, Francisco. Amizade e estética da existência em Foucault. Rio de Janeiro, RJ: Graal, 1999.

PLATÃO. Fedro. Tradução de Maria Cecília Gomes dos Reis. $1^{\text {a }}$ Ed. São Paulo: Penguin Classics Companhia das Letras, 2016.

PLATÃO. Carta VII. Tradução de José Trindade Santos e Juvino Maia Jr. Rio de Janeiro: Ed. PUC-Rio; São Paulo: Loyola, 2008.

RANCIÈRE, Jacques. Políticas da Escrita. 1ª ed. Rio de Janeiro: Ed. 34, 1995.

TRABATTONI, Franco. Oralidade e escrita em Platão. São Paulo: Discurso editorial, 2003.

TRABATTONI, Franco. Platão. São Paulo: Annablume, 2010. 